\title{
New applications of r.f.-sputtered glass films as protection and bonding layers in silicon micromachining
}

\author{
J.W. Berenschot, J.G.E. Gardeniers, T.S J Lammerınk and M Elwenspoek \\ Untversity of Twente, MESA Research Instzute, PO Box 217, 7500 AE Enschede (Netherlands)
}

\begin{abstract}
Different $\mathrm{r} f$-sputtered borosilicate glass films are charactenzed Layers sputtered in $100 \%$ Ar and annealed in $\mathrm{N}_{2}$ at $550^{\circ} \mathrm{C}$ for $35 \mathrm{~h}$ are found to be best applicable as protection layers in anisotropic etching of Si in KOH solutions and as bonding layers in silicon micromachining For $i n$ situ inspection of the progress of the sliconto-silicon anodic bonding process using sputtered glass as intermediate layer, an infrared inspection equipment is built Also, an alternative evaluation method of the bonding quality is presented Bonding experiments with sputtered glass layer thicknesses ranging from 20 to $1000 \mathrm{~nm}$ show corresponding progress of the bondmg process The yield does not seem to depend on the thickness of the borosilicate layer Furthermore, new possible applications are demonstrated, in which the sputtered glass layer acts both as an etch stop and bonding layer
\end{abstract}

\section{Introduction}

Silicon-to-sliscon wafer bonding is one of the key technologies in silicon micromachining Several bonding methods have been developed during recent years, $\mathrm{e} \mathrm{g}$, silicon fusıon bonding [1], anodic bonding [2], low temperature boron oxide glass bonding [3] The first has the disadvantage of requiring a high temperature step to achieve a strong bond This means that device realization is limited to materials and process steps which can withstand high temperature Devices fabricated with the latter bonding technique can only operate in nonaqueous environments, otherwise the bonding immerses Also, wet process steps after bonding are out of the question

Anodic bonding of two silicon wafers using a sputterdeposited glass film is a very promising technique, which does not suffer from the above-mentioned disadvantages After the invention in 1972 by Brooks and Donovan [4] extensive work has been done to develop this technique Typical parameters for proper bonding were found to be thickness of the sputtered layer ranging from 05 to $4 \mu \mathrm{m}$, applied voltage in the order of $30-200 \mathrm{~V}$ and temperatures from room temperature to $450{ }^{\circ} \mathrm{C}$ Wafers with a sputtered glass thickness of less than $05 \mu \mathrm{m}$ could not be bonded, although the bonding procedure did not seem to depend on the thickness of the thin film [5]

In this paper we report on our first bonding experiments with layer thicknesses in the range of 20 to $1000 \mathrm{~nm}$ For $i n$ situ inspection of the bonding procedure infrared camera equipment is used Another point of investigation is the use of the sputtered glass films as masking layers in anisotropic etching of $\mathrm{S}_{1}$ in $\mathrm{KOH}$ solutions This opens up the possibility of developing process schemes in which bonding and etchback are combined As will be demonstrated, it also allows the evaluation of the bonding quality by etchback procedures

\section{Characterization of sputtered glass layers}

The glass layers were deposited by $\mathrm{r} f$-diode sputterng with a Nordiko 2000 system Schott 8330 glass was used as target The properties of this glass are comparable with those of Cornıng \#7740 glass All layers were sputtered at the following conditions sputter pressure of $1 \mathrm{~Pa}$ and target $\mathrm{r} f$ power density of 27 $W / \mathrm{cm}^{2}$ The composition of the sputter gas was varied, leaving the other parameters constant Sputtering was carned out in $100 \% \mathrm{Ar}, 10 \% \mathrm{O}_{2} / 90 \%$ Ar or $25 \% \mathrm{O}_{2} /$ $75 \%$ Ar The deposition rate depends strongly on the composition of the gas (see Table 1) Addition of $10 \%$ oxygen to the sputter gas lowers the deposition rate by 35\% Davidse and Massel [6] and Hanneborg and Nese [7] report on a sumilar effect The stress in the films was determined by wafer curvature measurements The measured values of the stress are shown in Table 1 Compared to thermal oxide the stress is smaller by a factor of three (steam oxidation, $0310 \mathrm{GPa}$ compressive stress [8]) It was found that the stress can 
TABLE 1 Deposition rate and stress of different sputtered layers

\begin{tabular}{|c|c|c|c|c|c|}
\hline \multirow[t]{2}{*}{ Sputtering gas } & \multirow{2}{*}{$\begin{array}{l}\text { Dep } \\
\text { rate } \\
(\mathrm{nm} / \mathrm{h})\end{array}$} & \multicolumn{2}{|c|}{ As deposited } & \multicolumn{2}{|c|}{$\begin{array}{l}\text { After annealing } \\
\text { at } 550^{\circ} \mathrm{C}\end{array}$} \\
\hline & & $\begin{array}{l}\text { Stress } \\
(\mathrm{MPa})\end{array}$ & Index & $\begin{array}{l}\text { Stress } \\
\text { (MPa) }\end{array}$ & Index \\
\hline $100 \% \mathrm{Ar}$ & 286 & 128 & 161 & 5 & 152 \\
\hline $90 \% \mathrm{Ar} / 10 \% \mathrm{O}_{2}$ & 186 & 91 & 150 & 76 & 150 \\
\hline $75 \%$ Ar/25\% $\mathrm{O}_{2}$ & 169 & 119 & 150 & & 150 \\
\hline
\end{tabular}

TABLE 2 Etch rate of different sputter-deposited glass layers

\begin{tabular}{lll}
\hline Sputterıng gas & $\begin{array}{l}\text { Etch rate } \\
(\mathrm{nm} / \mathrm{h})\end{array}$ & $\begin{array}{l}\text { Etch rate after annealing } \\
(\mathrm{nm} / \mathrm{h})\end{array}$ \\
\hline $100 \% \mathrm{Ar}$ & 268 & 208 \\
$90 \% \mathrm{Ar} / 10 \% \mathrm{O}_{2}$ & 380 & 268 \\
$75 \% \mathrm{Ar} / 25 \% \mathrm{O}_{2}$ & 334 & 238 \\
\hline
\end{tabular}

be lowered by annealing in a nitrogen ambient at a temperature of $550^{\circ} \mathrm{C}$ and an annealing time of at least $35 \mathrm{~h}$ First annealıng experıments show a difference in stress reduction between layers sputtered in a $100 \%$ argon ambient and layers sputtered with an addition of oxygen to the sputter gas Annealing of layers sputtered in $100 \%$ argon ambient gives a $96 \%$ reduction of the compressive stress Annealing of sputtered layers with an addition of $10 \%$ oxygen to the sputter gas shows only a reduction of the compressive stress by $16 \%$ under the same conditions of annealing

The refractive index of the layers was measured to be 150 for layers sputtered in an oxygen-containing ambient and 161 for $100 \%$ argon sputtered layers Only the refractive index of $100 \%$ argon-sputtered layers changes during annealing It decreases from 161 to 152

To determine the etch rate of the deposited glass films in a $25 \mathrm{wt} \% \mathrm{KOH}$ solution, the thicknesses of the sputtered layers were measured by scanning electron microscopy (SEM) before and after etching in $\mathrm{KOH}$ From these results the etch rates were calculated The results are shown in Table 2 The temperature of the $\mathrm{KOH}$ solution was $79^{\circ} \mathrm{C}$

As can be seen, the etch rate strongly depends on whether the layers are annealed at $550{ }^{\circ} \mathrm{C}$ for $35 \mathrm{~h}$ or not Note, that especially for the $100 \%$ Ar-sputtered layers the annealing decreases the compressive stress, the refractive index and also the etch rate in $\mathrm{KOH}$ $A$ reason could be densification The annealed layers sputtered in $100 \%$ argon show an etch rate which is significantly lower than that of thermally grown $\mathrm{SiO}_{2}$ Thermal oxide is well known as a masking layer in anisotropic etching of $\mathrm{S}_{1}$ in $\mathrm{KOH}$ solutions The etch rate of thermal oxide is $280 \mathrm{~nm} / \mathrm{h}$ under the same conditions The etch rate of the deposited films increases when oxygen is introduced in the sputtering gas The lower etch rate of the layers sputtered in a $100 \%$ argon ambient is probably caused by the presence of a larger amount of boron in the glass layer compared to the layers which are sputtered in ambients with an addition of oxygen Boron is known to decrease the etch rate of silicate glasses

When a $850 \mathrm{~nm}$ glass layer is etched for $2 \mathrm{~h}$ in 25 wt $\% \mathrm{KOH}$ at a temperature of $78^{\circ} \mathrm{C}$ no pinholes are observed A layer, which is etched to a thickness of $35 \mathrm{~nm}$, has a pinhole density of 7 pinholes $/ \mathrm{mm}^{2}$ Therefore, the sputtered 8330 glass layer can be used as an etch stop or etch mask in anisotropic etching of $S_{1}$ with $\mathrm{KOH}$

\section{Silicon-to-silicon anodic bonding experiments}

\section{Set-up}

The equipment used for anodic bonding of two silicon wafers is shown in Fig 1 An additional option of this set-up compared to commonly used bonding equipments is the in situ infrared inspection The heating element is used as an infrared source for inspection, which makes an extended infrared source unnecessary To obtain a better contrast in the infrared mage a 3 inch molybdenum plate is inserted as a filter between the heater and the wafer pair A tilted silicon wafer acts as infrared mirror The bonding current can be derived from voltage measurements over a known resistor

\section{Cleaning and bonding}

Prior to bonding both wafers are cleaned in a cleanroom environment (class 100 ) by a two-step cleaning process 10 min fuming nitric acid followed by deionized water rinsing and $15 \mathrm{~min}$ boiling nitnc acid (70\%) After rinsing in deionized water the wafers are dried by spinning Immediately after this cleaning step the wafers are joined together without alıgning and then placed on the heating element Bonding takes place when a negative voltage is applied to the sputter-coated wafer at an elevated temperature

\section{In stu observation}

A $1 \mu \mathrm{m}$ thick layer which is sputter-deposited in $100 \%$ argon and annealed in nitrogen is bonded to a wafer The progress of the bonding process at eight points of time is shown in Fig 2 Figure 2(a) is the infrared image of the wafer pair at $450^{\circ} \mathrm{C}$, without an electrical field Apparently there are two dust particles We see in Fig 2(b) that bonding starts when a voltage of $8 \mathrm{~V}$ is applied Figure 2(c) and (d) shows the progress after 22 and $37 \mathrm{~s}$, respectively No further bonding occurs after $37 \mathrm{~s}$ By increasing the voltage in steps of 


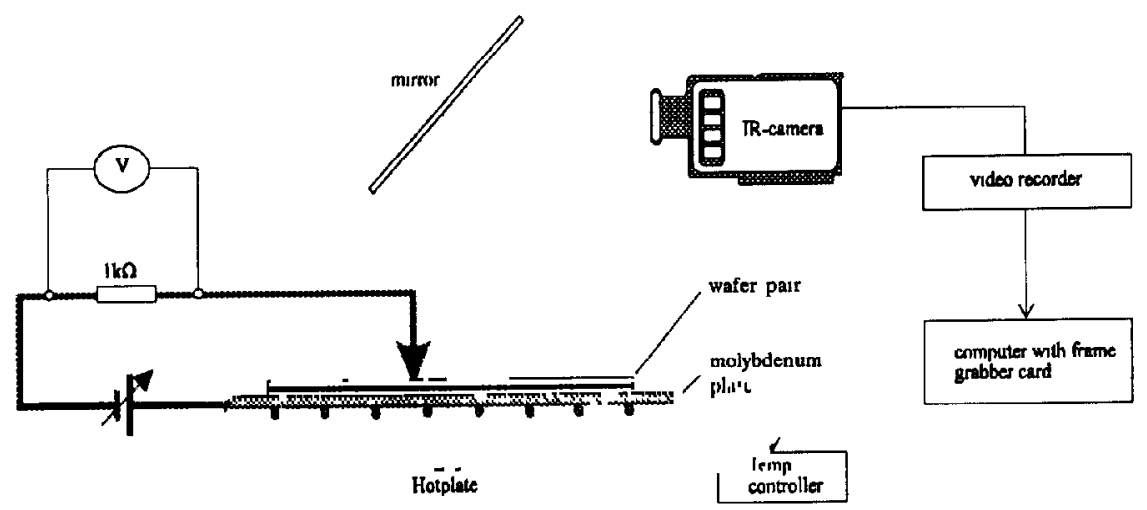

Fig 1 Expenmental set-up

$100 \mathrm{mV}$, bonding contınues at $10 \mathrm{~V}$ (Fig 2(e)) In Fig 2(f)-(h) it can be seen that it is possible to manipulate the bonding process manually, by applying an external force at the bonding front with a probe pen on the backside of the upper wafer In this way it is possible to avold large enclosures of trapped gas Voids caused by dust particles remain, but can be made smaller in this way At $10 \mathrm{~V}$ the whole wafer is bonded Figure 2(1) shows an infrared mage of the wafer pair at room temperature A halogen lamp is used as infrared source No difference can be observed between the infrared 1mage at $450{ }^{\circ} \mathrm{C}$ and room temperature

\section{Evaluation of the bonding qualty}

It is possible to verify infrared pictures of the bonding by etchback of the sputter-coated wafer completely When bonding occurs at $1 \mathrm{~atm}$ the unbonded regions contain trapped gas under a high pressure. After complete backetching of the sputter-coated wafer in $\mathrm{KOH}$, the etch process stops at the borosilicate layer Due to the gas pressure in the unbonded regions these regions bulge Large unbonded regions crack and can be optically detected very easily because the silicon underneath the film is etched very fast (see Fig 3)

For inspection of the bonding quality, the wafer pair mentioned in Section 33 is sawed into two pieces After backetching the nght half of the wafer in $\mathrm{KOH}$ it can be seen in Fig 2(j) that the volds agree with the spots in the infrared image of Fig 2(1) The serrated edge is just over the two voids in the middle, so we can also use the characterization method of voids by etching the cross section in $\mathrm{KOH}$, according to Mitanı et al [9] The cross section is etched faster on places where the voids are located, because of being ummersed in $\mathrm{KOH}$ and being etched there preferentually

\section{Results and discussion of thin layer bonding}

First experiments are carned out with sputtered glass layers of thicknesses of 120,210 and $430 \mathrm{~nm}$ Bonding to bare silicon wafers occurs at 1,1 and $4 \mathrm{~V}$, resp , at a temperature of $450^{\circ} \mathrm{C}$ Because these experiments are carried out without the in situ infrared inspection, it is impossible to see if the complete wafer is bonded, but infrared inspection afterwards shows that the wafers are only partly bonded $\mathrm{KOH}$-backetching confirms the infrared mage We have not yet developed a method to determine quantitatively the strength of the bond Destructive experiments are carned out by inserting a razor blade between the wafers and breaking them apart In the case of layer thicknesses of 210 and 430 $\mathrm{nm}$ the fracture occurs in the sputtered glass layer This indicates that the bond formed is stronger than the cohesive forces in the glass layer The sample with layer thickness of $120 \mathrm{~nm}$, however, breaks mainly along the sputtered glass layer/silicon interface, leavng small circular portions of the sputtered layer on the substrate This indicates that the bond formed is stronger than the bonds at the interface between the sputtered glass layer and the slicon wafer

Recent experiments with layer thicknesses ranging from 20 to $800 \mathrm{~nm}$ result in comparable bonding sequences as shown in Fig 2 The layers are sputtered in $100 \%$ argon and not annealed The yield does not at all seem to depend on the thickness of the borosilicate glass layer, which puts doubts on the suggested mechanism of anodic bonding for the cases of very thin films anodic bonding is supposed to work because, at elevated temperature, the glass layer becomes conductive due to an increased mobility of $\mathrm{Na}^{+}$ions A voltage then gives rise to a depletion layer at the surface of the glass layer and, hence, there is a large electrostatic force between the wafers However, as has been outlined by Anthony [10], if there is a dielectric thin film between wafers of a thickness comparable to the thickness of the depletion layer in the sputtered glass film, the electrostatic force will be comparable Therefore, if thin films become thin enough, the migration of the $\mathrm{Na}^{+}$ions becomes less important in the bonding process 

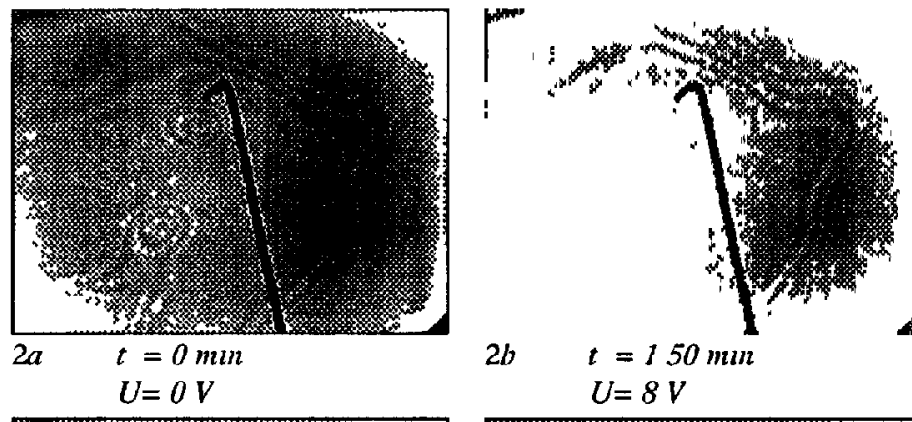

$2 b \quad t=150 \mathrm{~mm}$

$$
U=8 \mathrm{~V}
$$
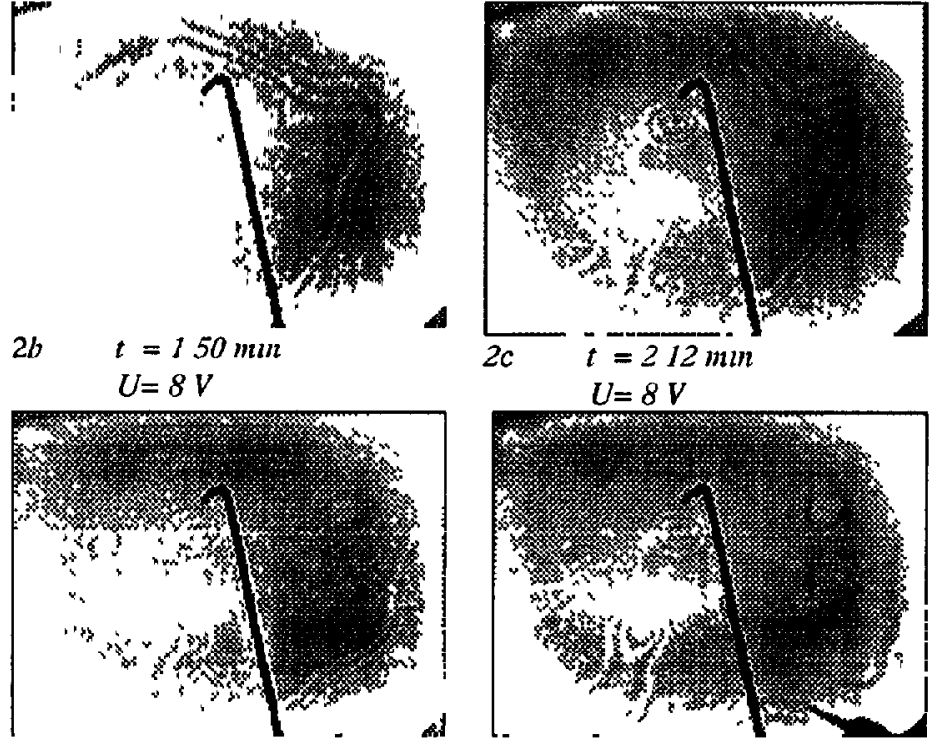

$2 d \quad t=227 \mathrm{~mm}$

$2 e$

$t=444 \mathrm{~mm}$

$2 c \quad t=212 \mathrm{~mm}$

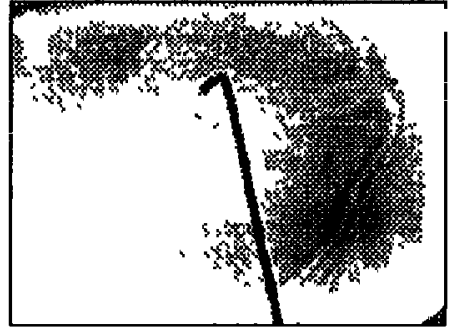

$U=8 \mathrm{~V}$

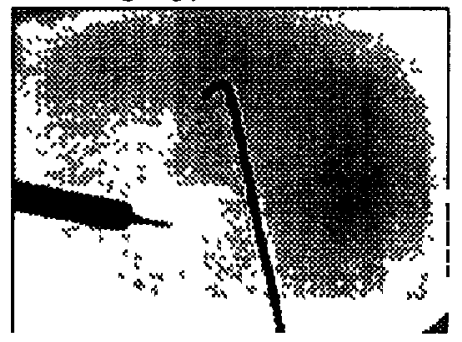

$2 g \quad t=554 \mathrm{~mm}$

$U=10 \mathrm{~V}$

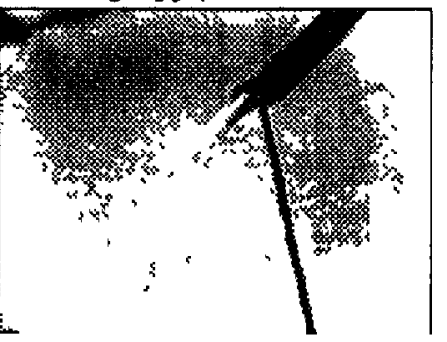

25

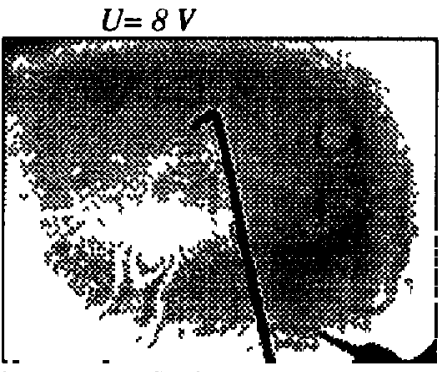

$i=519 \mathrm{~mm}$

$U=10 \mathrm{~V}$

$2 \mathrm{~h} \quad t=615 \mathrm{~mm}$

$U=10 \mathrm{~V}$
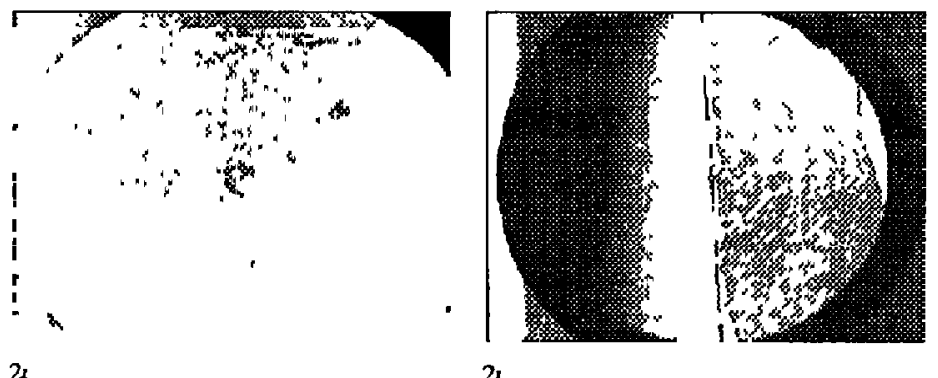

Fig 2 (a)-(h) In stu infrared pictures of the bond process at different times lamp as infrared source (j) Normal picture of half a wafer after backetching

(1) Infrared picture after bonding with a halogen

This observation suggests that anodic bonding should also be possible if there are only thin layers of native (or thermally grown) oxide

\section{Applications}

To demonstrate possible applications, we realized sealed chambers by using a sputtered glass layer both as etch stop and as bonding layer (see Fig 4(a)) In one of the two sllicon wafers, $10 \mu \mathrm{m}$ deep wells are etched The other wafer contans a sputter-deposited glass layer, whuch later forms the cavty-confining film After anodic bonding of the two wafers at $450^{\circ} \mathrm{C}$ (I), the wafer on which onginally the glass layer was sputtered is removed completely by wet chemical etching in KOH (II) The glass layer acts as an etch stop (III) This technique is used to produce cavities with a sealed 


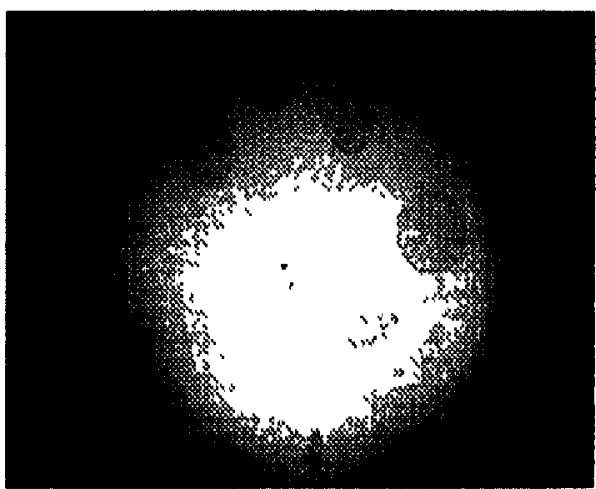

(a)

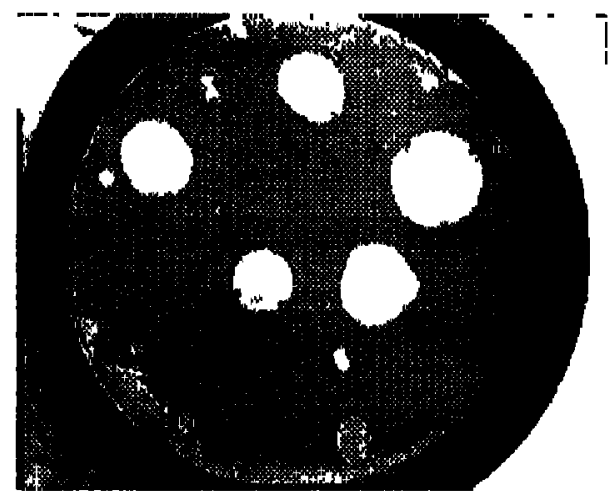

(b)

Fing 3 Infrared image of bonded wafer (a) and image after backetching in $\mathrm{KOH}$ (b)

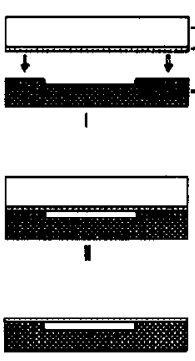

III

(a)

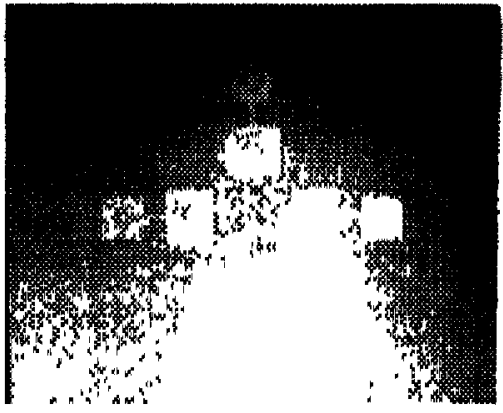

(b)

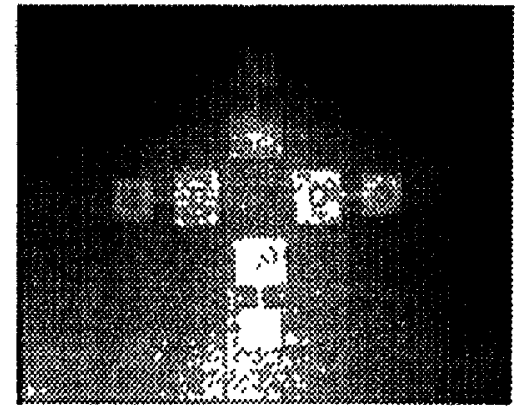

(c)

Fig 4 (a) Process to produce a sealed cavity (b) Image of four sealed cavities Each cavity consists of two chambers (100 $\mu \mathrm{m}^{2}$ and $80 \mu \mathrm{m}^{2}$ ) connected by a $20 \mu \mathrm{m}$ wide channel (c) Image of the same cavities as shown in Fig $4(\mathrm{~b})$, after exposure of the upper cavity to 1 atm No interference fringes can be observed in this cavity

area of up to $1 \mathrm{~mm}^{2}$ As can be seen from interference fringes in Fig 4(b), the layer bends down In the case of glass layers, which contain a very low compressive stress $(100 \%$ argon sputtered, nitrogen annealing at $550{ }^{\circ} \mathrm{C}, 35 \mathrm{~h}$ ), the main reason is the under-pressure in the cavity This is concluded by scanning the surface of a $100 \mu \mathrm{m}^{2}$ sealed cavity before and after exposure of the cavity to $1 \mathrm{~atm}$, see $\mathrm{Fig} 4(\mathrm{~b})$ and (c) The measurements are carried out with a surface profiler (Sloan Dektak 3030) Before exposure the maximum bending is $459 \mathrm{~nm}$ and after exposure it is $188 \mathrm{~nm}$ The needle force of the profiler is $001 \mathrm{~N} \mathrm{~N}$ interference fringes can be observed after exposure to $1 \mathrm{~atm}$ which also indicates that the under-pressure is the main reason

Concerning the as-sputtered glass layers which contain compressive stress, however, the interference frnges are caused by the combination of under-pressure and buckling of the membrane The maximum bending amplitude after backetching was found to be $1 \mu \mathrm{m}$, the same as the depth of the cavity Exposure to 1 atm results in buckling of the film in an upward direction with a maximum deflection of $4 \mu \mathrm{m}$
Using the sputtered glass layer both as bonding layer and etch stop results in the following process possibulities

(1) Very shallow sealed cavities can be realized (less than $100 \mathrm{~nm}$ ) No stıcking occurs in the cavity because the glass film joins the upper sulicon wafer durng bonding

(2) Very deep cavities can be sealed ( $>100 \mu \mathrm{m}$ )

Process possibility (1) is used to create electrostatic actuators like active joints, proposed by Elwenspoek et al [11] An active joint consists of two plates, one of which is a bilayer and bent by the bimorph effect At one edge the plates are clamped together (see Fig 5) It is essential that large electrostatic forces acting over a short distance are used to produce large deflections

In the light of processing a shallow cavity with a patterned metal layer, deposited in the cavity pror to bonding, the next step is to create the sealed cavity by bonding and backetching After this the bimorph is made by depositing an aluminum layer on the glass layer at an elevated temperature The expansion coefficient of the aluminum is larger than that of the glass 


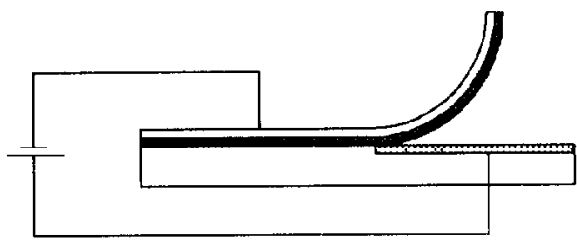

(a)

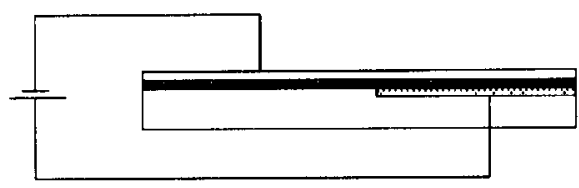

(b)

Fig 5 Schematic of the active joint The bilayer on top of the structure is bonded left of the bottom electrode and free above the electrode (a) unactivated, (b) activated

layer The last step is to pattern the bimorph This can be done by patterning the aluminium by photolithography and subsequently etching aluminium by a commercial etchant This pattern in aluminum can then serve as a mask for etching the glass layer by reactive ion etching (RIE)

At this stage an unexpected phenomenon occurs Our first attempts to etch the glass layer by RIE failed when $\mathrm{SF}_{6}$ or $\mathrm{CHF}_{3}$ was used as etch gas This is unexpected because RIE of the sputtered glass layer before bonding shows an etch rate of $110 \mathrm{~nm} / \mathrm{min}$ in $\mathrm{SF}_{6}(50 \mathrm{sccm}, 10 \mathrm{mTorr}, 100 \mathrm{~W}$ ) and $44 \mathrm{~nm} / \mathrm{min}$ in $\mathrm{CHF}_{3}(25 \mathrm{sccm}, 40 \mathrm{mTorr}, 100 \mathrm{~W}$ ) The reason may be formation of a micromask caused by non-volatile component accumulation Bonding could be the reason of the accumulation $\mathrm{Na}^{+}$ions are pushed to the topside of the layer when the voltage is applied and stay there This will be investigated in the near future Patterning the bimorph before bonding may solve this problem

Sealing of deep cavities is useful in cases where planarization of wafers containing deep cavities is required for additional lithographic steps [12]

\section{Acknowledgements}

The authors would like to thank Marc Weustınk for his research on bonding of thin layers and for realizing the experimental set-up

\section{References}

1 J B Lasky, Wafer bonding for silicon on insulator, Appl Phys Lett , 48 (1986) 78-80

$2 \mathrm{G}$ Wallis and D I Pomerantz, Field assisted glass-metal sealung, J Appl Phys, 40 (1969) 3946-3949

3 R Legtenberg, S Bouwstra and M Elwenspoek, Low-temperature glass bonding for sensor applications using boron oxıde thin films, $J$ Micromech Microeng, 1 (1991) 157-160

4 A D Brooks and R P Donovan, Low temperature electrostatic S1-to-Si seals using sputtered borosilicate glass, $J$ Electrochem Soc, 119 (1972) 545-546

5 M Esashi, A Nakano, S Shojl and H Hebiguch,, Low temperature silicon-to-silicon bonding with intermediate low meltung point glass, Sensors and Actuators, A21-A23 (1990) 931-934

6 P D Davidse and L I Maissel, Dielectric thin films through If sputtering, $J$ Appl Phys, 37 (1965) 547-579

7 A Hanneborg and $M$ Nese, Silicon to thin film anodic bonding, Tech Digest, MME '92, Leuven, Belgum, June 1992, pp 100-107

8 G Smolınsky and T P H F Wendling, Measurements of temperature dependent stress of silicon oxide films prepared by a variety of CVD methods, $J$ Electrochem Soc, 132 (1985) 950-954

9 K Mitanı, V Lehmann, R Stengl, D Feıjoo, U M Gösele and $\mathrm{HZ}$ Massoud, Causes and prevention of temperaturedependent bubbles in slicon wafer bonding, Jpn $J$ Appl Phys, 30 (1991) 615-622

10 T R Anthony, Anodic bonding of imperfect structures, $J$ Appl Phys, 54 (1983) 2419-2428

11 M Elwenspoek, L Smith and B Hök, Actıve joints for microrobot limbs, J Micromech Microeng, 2 (1992) 221-223

12 VL Spiering, JW Berenschot, $M$ Elwenspoek and $\mathrm{J} \mathrm{H} \mathrm{J}$ Flutman, Low temperature sacrificial wafer bonding for planarization after very deep etching, Proc Micro Electro Mechanucal Syst (MEMS '94), Kanagawa, Japan, Jan 25-28, 1994 